\section{Identification of Lifelines participants at high risk for development of rheumatoid arthritis}

We would like to thank Michael Mahler ${ }^{1}$ for his letter, 'Population-based screening for anticitrullinated protein antibodies (ACPA): A step in the pathway to the prevention of rheumatoid arthritis?' In his letter, Dr Mahler makes a plea to analyse and define reliable biomarkers to identify subjects who are on the trajectory to develop rheumatoid arthritis (RA). We agree with this notion of $\mathrm{Dr}$ Mahler as current efforts are increasingly focusing on the possibility to install early preclinical treatment to prevent progression to RA. For example, several randomised placebo-controlled trials (RCTs) have been initiated recently. These clinical trials will investigate the therapeutic potential of several immunomodulatory agents such as rituximab (PRAIRI study: NTR No. 1969), abatacept (APIPPRA study: ISRCTN No. 46017566 and ARIAA study: EudraCT No. 2014-000555-93), hydroxychloroquine (StopRA trial: NCT No. 02603146) and methotrexate (TREAT EARLIER: NTR No. 4853) in individuals at risk of RA. A study evaluating the immunomodulatory effect of atorvastatin in patients with seropositive arthralgia has also been initiated (STAPRA study: NTR No. 22389).

Our publication contributes to these and other efforts as it describes the presence of a prominent biomarker for RA, ACPAs, in a large population-based study and thereby aids to the development of predictive algorithms identifying individuals at risk for RA development. As outlined in this publication, we determined the prevalence of ACPA positivity and its association with known RA risk factors in 40136 participants from the Lifelines cohort. $^{2}$ Lifelines is a large ongoing prospective population-based cohort study and biobank to investigate the interaction between environmental and genetic factors in the development of chronic diseases. The standardised protocol includes physical examination, extensive questionnaires, and biobanking of serum, plasma, urine and DNA. Participants will be followed up according to a fixed protocol for at least 30 years. ${ }^{3}{ }^{4}$ Within the existing infrastructure, additional collection of data and additional studies in already biobanked and future samples can be performed. For example, the composition of the microbiome is currently being analysed in over 900 subjects participating in the Lifelines deep cohort, ${ }^{5}$ eventually facilitating the contribution of the microbiome composition to the risk to develop RA. Likewise, genetics such as whole genome sequencing including human leukocyte antigen (sub-) typing can be performed, thereby allowing the analyses of the contribution of the microbiome in the susceptible genetic background to the development of autoimmunity. ${ }^{6}$ Other described predictive markers like the acute-phase reactants erythrocyte sedimentation rate and $\mathrm{C}$ reactive protein and additional markers can be incorporated in the development of prediction models. Indeed, recent insight into the specificity of the combined presence of ACPA, rheumatoid factor and anticarbamylated protein antibodies provides interesting possibilities in further narrowing down persons at risk. ${ }^{78}$

Overall, Lifelines will give us the unique opportunity to gain follow-up information on our study population. With funding, it will be possible to measure additional biomarkers as indicated above. Therefore, this cohort is well suited for subsequent analyses on other biomarkers and risk factors, as also advocated by Dr Mahler.

Our future goal is to build a prediction model that can distinguish participants at high risk from those at low risk to develop
RA. Such a model is relevant because both animal data and clinical data suggest that prevention of RA may be possible and early treatment aiming at drug-free remission is possible. ${ }^{9} 10$

The performance of RCTs on preventive treatment strategies in individuals at risk for RA is challenging. The development of reliable assays and predictive algorithms to define a population with high enough at risk is crucial to allow the design of effective preventive therapy aiming to restore immune homeostasis with a great specificity, low toxicity and long-term effectiveness.

\section{S Arends, ${ }^{1}$ L A Trouw, R E M Toes, ${ }^{2}$ A van Zanten, ${ }^{2,1}$ C Roozendaal, ${ }^{3}$ P C Limburg, H Bootsma, ${ }^{3,1}$ E Brouwer $^{1}$}

${ }^{1}$ Department of Rheumatology and Clinical Immunology, University Medical Center Groningen, University of Groningen, Groningen, The Netherlands

${ }^{2}$ Department of Rheumatology, Leiden University Medical Center, Leiden, The Netherlands

${ }^{3}$ Department of Laboratory Medicine, University Medical Center Groningen, University of Groningen, Groningen, The Netherlands

Correspondence to Dr E Brouwer, Department of Rheumatology and Clinical Immunology, University Medical Center Groningen, University of Groningen, Groningen 9713GZ, The Netherlands; e.brouwer@umcg.nl

Competing interests None declared.

Provenance and peer review Commissioned; internally peer reviewed.

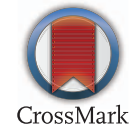

To cite Arends S, Trouw LA, Toes REM, et al. Ann Rheum Dis 2017;76:e43.

Accepted 15 February 2017

Published Online First 8 March 2017

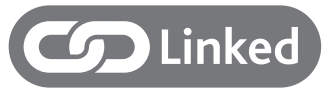

- http://dx.doi.org/10.1136/annrheumdis-2017-211249

Ann Rheum Dis 2017;76:e43. doi:10.1136/annrheumdis-2017-211256

REFERENCES

1 Mahler M. Population based screening for ACPA: a step in the pathway to the prevention of rheumatoid arthritis? Ann Rheum Dis 2017;76:e42.

2 Van Zanten A, Arends S, Roozendaal C, et al. Presence of anticitrullinated protein antibodies in a large population-based cohort from the Netherlands. Ann Rheum Dis 2017. doi:10.1136/annrheumdis-2016-209991 [Epub ahead of print: 2 Jan 2017].

3 Scholtens S, Smidt N, Swertz MA, et al. Cohort Profile: Lifelines, a three-generation cohort study and biobank. Int J Epidemiol 2015;44:1172-80.

4 Klijs B, Scholtens S, Mandemakers JJ, et al. Representativeness of the Lifelines Cohort Study. PLOS ONE 2015;10:e0137203.

5 Bonder MJ, Kurilshikov A, Tigchelaar EF, et al. The effect of host genetics on the gut microbiome. Nat Genet 2016;48:1407-12.

6 van Heemst J, Jansen DTSL, Polydorides S, et al. Crossreactivity to vinculin and microbes provides a molecular basis for HLA-based protection against rheumatoid arthritis. Nat Commun 2015;6:6681.

7 Shi J, van Steenbergen HW, van Nies JA, et al. The specificity of anti-carbamylated protein antibodies for rheumatoid arthritis in a setting of early arthritis. Arthritis Res Ther 2015:17:339.

8 Koppejan H, Trouw LA, Sokolove J, et al. Role of anti-carbamylated protein antibodies compared to anti-citrullinated protein antibodies in indigenous North Americans with rheumatoid arthritis, their first-degree relatives, and healthy controls. Arthritis Res Ther 2016;68:2090-8.

9 Dekkers JS, Schoones JW, Huizinga TW, et al. Possibilities for preventive treatment in rheumatoid arthritis? Lessons from experimental animal models of arthritis: a systematic literature review and meta-analysis. Ann Rheum Dis 2017;76:458-67.

10 Ajeganova S, van Steenbergen HW, van Nies JA, et al. Disease-modifying antirheumatic drug-free sustained remission in rheumatoid arthritis: an increasingly achievable outcome with subsidence of disease symptoms. Ann Rheum Dis 2016;75:867-73 